\title{
CrystEngComm
}

Cite this: CrystEngComm, 2014, 16 2802

Received 27th September 2013 Accepted 19th November 2013

DOI: $10.1039 / c 3 c e 41957 f$

www.rsc.org/crystengcomm

\section{Synthesis and single crystal growth of L-proline cadmium chloride monohydrate and its characterization for higher order harmonic generation applications}

\author{
Kanika Thukral, ${ }^{a}$ N. Vijayan, ${ }^{* a}$ Brijesh Rathi, ${ }^{\text {b }}$ G. Bhagavannaryana, ${ }^{\text {a }}$ Sunil Verma, ${ }^{\text {c }}$ \\ J. Philip, 'A Anuj Krishna, ${ }^{a}$ M. S. Jeyalakshmy ${ }^{d}$ and S. K. Halder ${ }^{a}$
}

\begin{abstract}
The semi-organic non linear optical single crystal of L-proline cadmium chloride monohydrate was successfully synthesized and the single crystal was grown by a slow evaporation solution growth technique, using double distilled water as the solvent. The lattice dimensions of the grown crystal were examined by powder X-ray diffraction and it was found to belong to the orthorhombic crystal system with a noncentrosymmetric space group. Its crystallinity was assessed by a high resolution X-ray diffraction method and its structural imperfections were recorded using $X$-ray topography. The presence of functional groups was identified from heteronuclear correlation methods. Its optical behavior was examined by birefringence and photoluminescence and its optical constants were determined from UV-Vis. analysis. Its thermal and third order nonlinear optical properties were characterised by photopyroelectric and Z-scan methods, respectively. The mechanical and ferroelectric behavior was also assessed on the grown single crystal of L-proline cadmium chloride monohydrate.
\end{abstract}

\section{Introduction}

Recently, non linear optics has become one of the most attractive areas for researchers, as it shows excellent applications for device fabrication in different fields of research. ${ }^{1-4}$ Even though many materials have nonlinear optical behavior, amino acids have the maximum possibility of showing non linear optical properties. In the present work, we report the growth and analysis of semiorganic L-proline cadmium chloride monohydrate (L-PCCM) single crystal. The above material has a high non-linearity, high resistance to laser induced damage, low angular sensitivity and increased mechanical hardness. In general, amino acids act as both an acceptor and donor i.e. through proton donating carboxyl $(-\mathrm{COOH})$ and proton accepting amino $\left(-\mathrm{NH}_{2}\right)$ groups. ${ }^{5,6}$ The title compound was grown by a slow evaporation solution growth (SEST) technique at room temperature. It crystallizes in the noncentrosymmetric space group of $P 2_{1} 2_{1} 2_{1}$ and its detailed bond lengths and bond distances have already been

\footnotetext{
${ }^{a}$ CSIR-National Physical Laboratory, Dr. K.S. Krishnan Road, New Delhi-110 012, India. E-mail: nvijayan@nplindia.org, vjnphy@yahoo.com; Fax: +91 11 45609310; Tel: +91 1145608263

${ }^{b}$ Department of Chemistry, Sri Venkateswara College, University of Delhi, New Delhi - 110021, India

${ }^{c}$ Laser Materials Development \& Devices Division, RRCAT, Indore, M.P., India

${ }^{d}$ Department of Instrumentation and STIC, Cochin University of Science and Technology, Cochin-682 022, India
}

reported. ${ }^{7}$ It is an excellent non-linear optical material, whose second harmonic generation (SHG) efficiency is twice that of potassium dihydrogen phosphate (KDP). ${ }^{8}$ Even though few reports are available on the title compound, there is no report available on the X-ray topography, HETCOR, photoluminescence, Z-scan or photopyroelectric measurements which are the crucial parameters for making optical related devices and the observed results were discussed in detail.

\section{Experimental}

\section{Synthesis and crystal growth}

The commercially available L-proline and cadmium chloride monohydrate were obtained and their purities were improved by repeated recrystallization processes. The purified salt was taken in a 1:1 stoichiometric ratio and the synthesis was carried out by a conventional chemical reaction as shown below using double distilled water as the solvent.

$$
\mathrm{CdCl}_{2} \cdot \mathrm{H}_{2} \mathrm{O}+\mathrm{C}_{5} \mathrm{H}_{9} \mathrm{NO}_{2} \rightarrow \mathrm{Cd}\left(\mathrm{C}_{5} \mathrm{H}_{9} \mathrm{NO}_{2}\right) \mathrm{Cl}_{2} \cdot \mathrm{H}_{2} \mathrm{O}
$$

The prepared solution was then filtered using Whatmann filter paper so that all the left impurities could be removed. The filtered solution was housed in a constant temperature bath (CTB) at $31{ }^{\circ} \mathrm{C}$ and monitored carefully. After a span of 30-35 days, good quality single crystals were harvested from the mother solution shown in Fig. 1. The grown specimen 


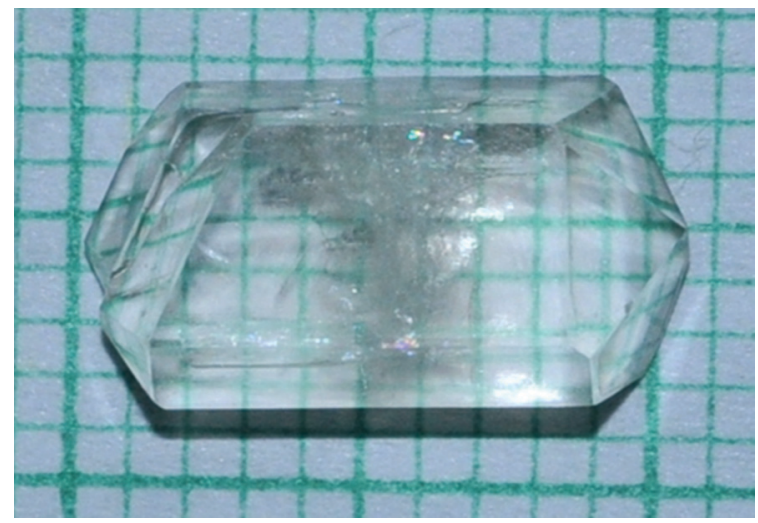

Fig. 1 Grown crystal of L-PCCM.

was cut and polished and then subjected to different characterization analyses.

\section{Characterization}

\subsection{Powder X-ray diffraction}

The grown single crystals of L-PCCM were crushed into a fine powder using an agate mortar in order to determine the lattice dimensions. The powdered sample was then subjected to a Bruker D8 Advance X-ray diffractometer with $\mathrm{CuK}_{\alpha}$ radiation $(\sim 1.54 \AA)$ and a scan speed of $0.1^{\circ} \mathrm{min}^{-1}$ over a $2 \theta$ range of $10^{\circ}$ to $80^{\circ}$. The recorded X-ray diffraction pattern is shown in Fig. 2. The observed $2 \theta$ values were used to calculate the lattice dimensions using chekcell software. The calculated lattice parameters are $a=9.9989 \AA, b=13.5310 \AA, c=7.2890 \AA$, $\alpha=\beta=\gamma=90^{\circ}$, which is good in agreement with the reported literature. ${ }^{7,8}$

Its polarizability and plasma energy have been calculated by taking into account its molecular weight (316.45 $\left.\mathrm{g} \mathrm{mol}^{-1}\right)$ and its total number of valence electrons $(Z=80)$. The density $(\rho)$ of the title compound is $2.13 \mathrm{~g} \mathrm{~cm}^{-3}$ and the dielectric constant $\left(\varepsilon_{\infty}\right)$ at $1 \mathrm{MHz}$ was found to be $20 .{ }^{9}$ The calculations were performed in the same manner as in the reported literature. ${ }^{10}$ The valence electron plasma energy $\hbar \omega_{\mathbf{P}}$ is given by

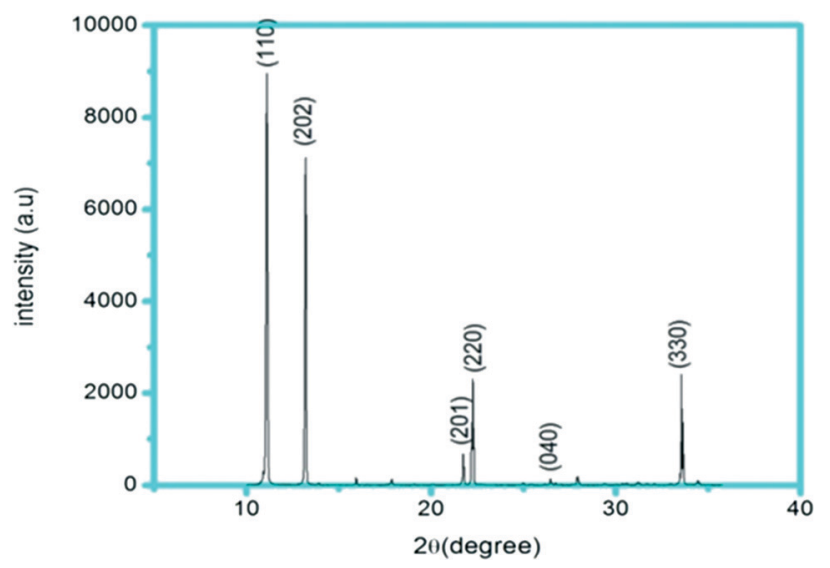

Fig. 2 Powder X-ray diffraction pattern of L-PCCM.

$$
\hbar \omega_{\mathrm{P}}=28.8 \sqrt{\frac{Z \rho}{M}}
$$

where $Z$ is the total number of valence electrons, $\rho$ is the density and $M$ is the molecular weight of the L-PCCM crystal. The plasma energy in terms of Penn gap and Fermi gap in $\mathrm{eV}$ is given as

$$
E_{\mathrm{P}}=\frac{\hbar \omega_{\mathrm{P}}}{\left(\varepsilon_{\infty}-1\right)^{\frac{1}{2}}}
$$

and

$$
E_{\mathrm{F}}=0.2948\left(\hbar \omega_{\mathrm{P}}\right)^{\frac{4}{3}}
$$

The polarizability, $\alpha$, from the Penn gap analysis is given by

$$
\alpha=\left[\frac{\left(\hbar \omega_{\mathrm{P}}\right)^{2} S_{\mathrm{O}}}{\left(\hbar \omega_{\mathrm{P}}\right)^{2} S_{\mathrm{o}}+3 E_{\mathrm{P}}{ }^{2}}\right] \times\left[\frac{M}{\rho}\right] \times 0.396 \times 10^{24} \mathrm{~cm}^{-1}
$$

where $S_{\mathrm{o}}$ is the constant for a particular material and is given by

$$
S_{\mathrm{o}}=1-\left[\frac{E_{\mathrm{P}}}{4 E_{\mathrm{F}}}\right]+\frac{1}{3}\left[\frac{E_{\mathrm{P}}}{4 E_{\mathrm{F}}}\right]^{2}
$$

The value of polarizability $\alpha$ is also be confirmed by using the Clausius-Mossotti relation, which is given as

$$
\alpha=\frac{3 M}{4 \Pi N_{\mathrm{a}} \rho}\left[\frac{\varepsilon_{\infty}-1}{\varepsilon_{\infty}+2}\right]
$$

The parameters which were calculated by using the above relations are given in Table 1.

\subsection{High resolution X-ray diffraction (HRXRD) analysis}

In this study, the defect free transparent single crystal of L-PCCM was characterized by HRXRD using a Rigaku double crystal X-ray diffractometer employing a $12 \mathrm{~kW}$ rotating anode X-ray generator. A (111) Si monochromator of $125 \mathrm{~mm}$ in diameter was aligned to the (333) reflection and highly monochromatic $\mathrm{CuK \alpha} \alpha_{1}$ radiation was obtained. X-rays from the $\mathrm{Cu}$ target were highly collimated using a $1.25 \mathrm{~m}$ vacuum collimator. A nearly perfect Si crystal aligned to the (440) reflection was used as the monochromator and the L-PCCM crystal as the second crystal in a $(+n,-m)$ configuration. The

Table 1 Some theoretical analysis data for L-PCCM

\begin{tabular}{ll}
\hline Parameters & Values \\
\hline Plasma energy $(\mathrm{eV})$ & 21.133 \\
Penn gap (eV) & 4.8492 \\
Fermi gap (eV) & 17.224 \\
Polarization $\left(\mathrm{cm}^{3}\right)$ Penn analysis & $5.092 \times 10^{-23}$ \\
Clausius-Mossotti equation & $5.0891 \times 10^{-23}$
\end{tabular}


detailed experimental setup was reported elsewhere. ${ }^{1,12}$ Before recording the diffraction curve and to remove the noncrystallized solute atoms remaining on the surface, lapping was performed using a non-preferential etchant of a water and acetone mixture in a $1: 2$ ratio. Fig. 3(a) shows the (440) rocking curve of the L-PCCM single crystal. The full width at half maxima (FWHM) is $\sim 35$ arcsec, which indicates that the crystal has good crystallinity. The topograph of the L-PCCM crystal was recorded at a distance of $80 \mathrm{~mm}$ from the crystal. The uniform intensity of the topograph confirms that the crystal is good and can be used for optical related devices (shown in Fig. 3(b)).

\subsection{Fourier transform infrared (FTIR) and RAMAN analyses}

The presence of functional groups were identified from FTIR analysis using the $\mathrm{KBr}$ pellet technique. The recorded spectrum is shown in Fig. 4. The peak appearing at $3487 \mathrm{~cm}^{-1}$ was assigned to the $\mathrm{O}-\mathrm{H}$ stretching vibration of $\mathrm{H}_{2} \mathrm{O}$. The peaks for the $\mathrm{N}-\mathrm{H}$ stretching vibration were observed at 3139 and $2729 \mathrm{~cm}^{-1}$. The absence of a peak at $1600 \mathrm{~cm}^{-1}$ for COO $(>\mathrm{C}=\mathrm{O})$ confirmed the zwitterionic form of the $\mathrm{COO}^{-}$ion. ${ }^{13}$ The peaks at 1595 and $1541 \mathrm{~cm}^{-1}$ were assigned to $\mathrm{NH}_{2}^{+}$in the plane deformation of L-PCCM. The peak at $1426 \mathrm{~cm}^{-1}$ was assigned as characteristic of the $\mathrm{NH}$ vibration. The peaks appearing at 1370, 1331 and $1282 \mathrm{~cm}^{-1}$ were assigned to wagging of the $\mathrm{CH}_{2}$ group. The peaks appearing in the range of 1229-828 $\mathrm{cm}^{-1}$ were assigned as (i) C-O stretching at $1229 \mathrm{~cm}^{-1}$, (ii) $\mathrm{NH}_{2}$ twisting at $1169 \mathrm{~cm}^{-1}$, (iii) $\mathrm{NH}_{2}^{+}$vibration at $1088 \mathrm{~cm}^{-1}$, (iv) C-N stretching at $1035 \mathrm{~cm}^{-1},(\mathrm{v}) \mathrm{CH}_{2}$ rocking at 983, 944, 864 and $828 \mathrm{~cm}^{-1}$ and (vi) $\mathrm{NH}_{2}$ rocking at $923 \mathrm{~cm}^{-1}$. The rocking vibrations of $\mathrm{COO}^{-}$were seen at 488 and $477 \mathrm{~cm}^{-1}$ however wagging appeared at $628 \mathrm{~cm}^{-1}$. In-plane deformation of $\mathrm{COO}^{-}$ and $\mathrm{CONH}_{2}$ were seen at 765 and $677 \mathrm{~cm}^{-1}$, respectively.

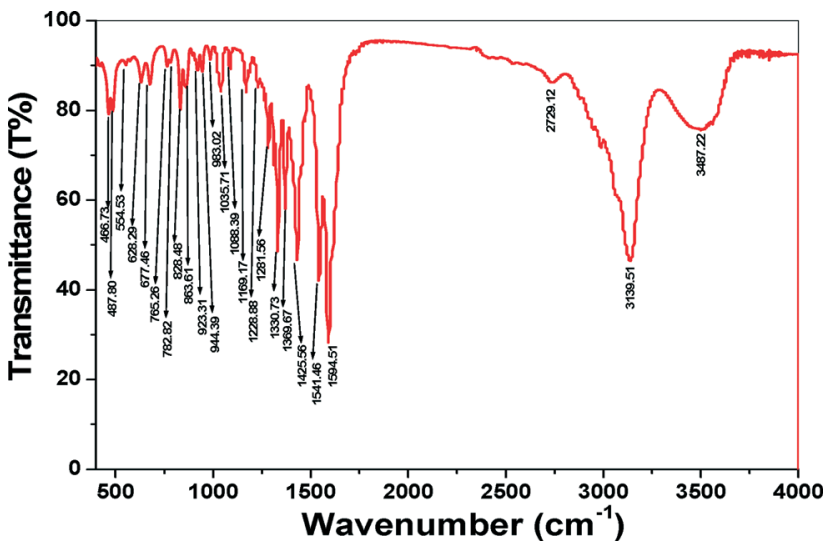

Fig. 4 FT-IR spectrum of L-PCCM.

The Raman spectrum of L-PCCM is shown in Fig. 5 and the observed peaks were assigned with the help of literature. ${ }^{9,14,15}$ The antisymmetric and symmetric stretching vibrations of the $\mathrm{NH}_{3}{ }^{+}$group were observed at 3195 and $3013 \mathrm{~cm}^{-1}$, respectively. Three $\mathrm{CH}$ stretching modes observed in the range of $2973-2891 \mathrm{~cm}^{-1}$ were assigned as $v_{\mathrm{a}}\left(\mathrm{CH}_{2}\right)$ at $2973 \mathrm{~cm}^{-1}, v(\mathrm{CH})$ at $2940 \mathrm{~cm}^{-1}$ and $v_{\mathrm{s}}\left(\mathrm{CH}_{2}\right)$ at $2891 \mathrm{~cm}^{-1}$. The observed peaks at 1616 and $1562 \mathrm{~cm}^{-1}$ were assigned to the bending modes of $\mathrm{NH}_{2}$ and $\mathrm{H}_{2} \mathrm{O}$ molecules, respectively. The antisymmetric and symmetric stretching vibrations of $\mathrm{COO}^{-}$were observed at 1480 and $1455 \mathrm{~cm}^{-1}$, respectively. A number of peaks observed in the $1413-1000 \mathrm{~cm}^{-1}$ region were assigned as (i) bending $\delta(\mathrm{CN})$ at $1413 \mathrm{~cm}^{-1}$, (ii) $\delta\left(\mathrm{CH}_{2}^{+}\right)$ at $1337 \mathrm{~cm}^{-1}$, (iii) wagging mode of $\omega\left(\mathrm{CH}_{2}\right)$ at $1288 \mathrm{~cm}^{-1}$, (iv) rocking mode of $r\left(\mathrm{NH}_{3}^{+}\right)$at $1186 \mathrm{~cm}^{-1},(\mathrm{v}) \omega\left(\mathrm{NH}_{2}\right)$ at $1089 \mathrm{~cm}^{-1}$ and (vi) $v_{\mathrm{a}}(\mathrm{CN})$ at $1045 \mathrm{~cm}^{-1}$. The vibrations for $\mathrm{C}-\mathrm{C}$ appeared at 981,939 and $898 \mathrm{~cm}^{-1}$. A sharp peak at $849 \mathrm{~cm}^{-1}$ was assigned to out-of-plane $\gamma\left(\mathrm{COO}^{-}\right)$. The three peaks

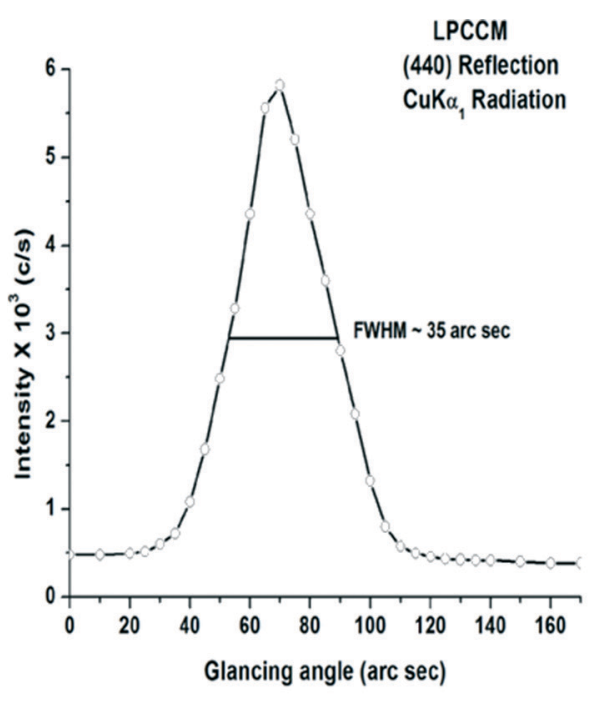

(a)

Fig. 3 (a) HRXRD (rocking curve) of L-PCCM. (b) Traverse topograph of grown crystal.



(b) 


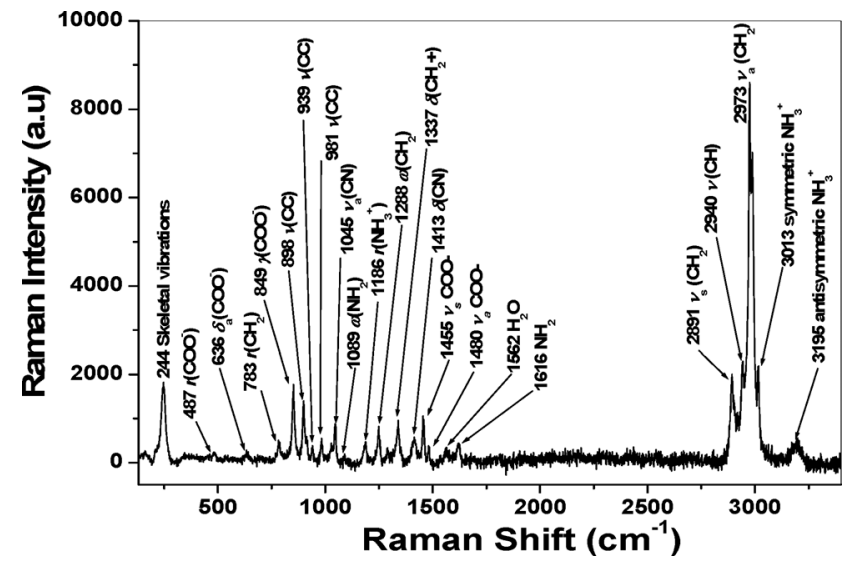

Fig. 5 Raman spectrum of L-PCCM.

appearing at 783, 686 and $487 \mathrm{~cm}^{-1}$ were assigned due to $r$ $\left(\mathrm{CH}_{2}\right), \delta_{\mathrm{a}}(\mathrm{COO})$ and $\delta(\mathrm{COO})$, respectively.

\subsection{Determination of dipole moment, static polarizability,} and first order hyperpolarizability

NLO techniques are considered as among the most structure potential of organic materials for NLO devices has been proven, NLO properties of many of these compounds have been investigated by both experimental and theoretical methods. ${ }^{17,18}$ Quantum chemical calculations have been sensitive methods to study molecular structures. ${ }^{16}$ Since the

first hyperpolarizability is a third rank tensor that can be described by a $3 \times 3 \times 3$ matrix. The 27 components of the $3 \mathrm{D}$ matrix can be reduced to 10 components due to the Kleinman symmetry, ${ }^{22}$ and can be given in the lower tetrahedral format. It is obvious that the lower part of the $3 \times 3 \times 3$ matrices is tetrahedral. The components of which are defined as the coefficients in the Taylor series, with expansion of the energy in the external electric field. When the external electric field is weak and homogeneous, this expansion becomes:

$$
E=E^{0}-\mu_{\alpha} F_{\alpha}-\frac{1}{2} \alpha_{\alpha \beta} F_{\alpha} F_{\beta}-\frac{1}{6} \beta_{\alpha \beta \gamma} F_{\alpha} F_{\beta} F_{\gamma}+\ldots
$$

Where $E^{0}$ is the energy of the unperturbed molecules $F_{\alpha}$ is the field at the origin, $\mu_{\alpha}, \alpha_{\alpha \beta}$ and $\beta_{\alpha \beta \gamma}$ are the components of the dipole moment, polarizability and the first hyperpolarizabilities, respectively. The total static dipole moment $\mu$, the mean polarizability $\alpha$, the anisotropy of the polarizability $\Delta \alpha$, and the mean first hyperpolarizability $\beta$, are defined as follows using the $x, y, z$ components:

$$
\begin{gathered}
\mu=\left(\mu_{x}{ }^{2}+\mu_{y}{ }^{2}+\mu_{z}{ }^{2}\right)^{\frac{1}{2}} \\
\langle\alpha\rangle=\frac{\alpha_{x x}+\alpha_{y y}+\alpha_{z z}}{3}
\end{gathered}
$$

$$
\beta_{\text {tot }}=\left[\left(\beta_{x x x}+\beta_{x y y}+\beta_{x z z}\right)^{2}+\left(\beta_{y y y}+\beta_{y z z}+\beta_{y x x}\right)^{2}+\left(\beta_{z z z}+\beta_{z x x}+\beta_{z y y}\right)^{2}\right]^{\frac{1}{2}}
$$

L-Proline cadmium chloride has a large dipole moment shown to be useful in the description of the relationship between the electronic structure of systems and their NLO response. ${ }^{19}$ The computational approach allows the determination of molecular NLO properties and is an inexpensive way to design molecules by analyzing their potential before synthesis and to determine high order hyperpolarizability tensors of molecules. The simplest polarizability $(\alpha)$ characterizes the ability of an electric field to distort the electronic distribution of a molecule.

The first hyperpolarizability $(\beta)$ of this novel molecular system, and the related properties $\left(\beta, \alpha_{0}\right.$ and $\left.\Delta \alpha\right)$ were calculated based on the finite-field approach. In the presence of an applied electric field, the energy of a system is a function of the electric field. Polarizability and hyperpolarizability characterize the response of a system in an applied electric field. ${ }^{18}$ They determine not only the strength of molecular interactions (long-range interaction, dispersion force, etc.) and the cross sections of different scattering and collision processes but also the NLO properties of the system. ${ }^{20,21}$ The Table 2, and a stronger dipole moment of L-proline cadmium chloride (for the calculation of DFT, we have taken $\mathrm{Cd}\left(\mathrm{C}_{5} \mathrm{H}_{9} \mathrm{NO}_{2}\right) \mathrm{Cl}_{2}$ as the molecular formula) leads to increased polarity. The different charge distributions result in completely different orientations of the (calculated) dipole moments. In Table 2, the results of the electronic dipole moment polarizabilities ( $\alpha$ and $\Delta \alpha$ ) and the first hyperpolarizability $(\beta)$ are listed.

Table 2 The mean polarizability $(\alpha)$, anisotropic polarizability $(\Delta \alpha)$, dipole moment $(\mu)$ and first-order hyperpolarizability $(\beta)$ values of the compound

$\begin{array}{ll}\alpha \text { (a.u.) } & 78.0804 \\ \Delta \alpha \text { (a.u.) } & 8.4236 \\ \mu \text { (debye) } & 10.1497 \\ \beta \text { (a.u.) } & 574.1571 \\ \beta \times 10^{-30} \text { esu } & 4.960 \\ \beta / \beta_{\text {urea }} & 25.475\end{array}$


The dipole polarizability indirectly provides a measure of the extent of distortion of the electron density, and hence the response of the system under the effect of an external static electric field. As shown in Table 2, the calculated polarizability figures $\alpha_{i j}$, have non-zero values and are dominated by the diagonal components. The calculated polarizability of the sample is equal to 78.0804 a.u. The first hyperpolarizability value $\beta$, of the compound is equal to $4.960 \times 10^{-30}$. As seen in Table 2, this value is 25.475 times that of urea $\left(0.1947 \times 10^{-30} \mathrm{esu}\right)$. These results indicate that this compound is a better candidate for use as a nonlinear optical material.

\subsection{NMR analyses}

${ }^{1} \mathrm{H}$ and ${ }^{13} \mathrm{C}$ NMR spectra were recorded on a JEOL ECX 400 NMR spectrometer operating at 400 and $100.0 \mathrm{MHz}$, respectively. Chemical shifts are reported in ppm relative to the signals of tetramethylsilane or residual solvent signals. ${ }^{1} \mathrm{H}$ and ${ }^{13} \mathrm{C} \mathrm{NMR}$, and heteronuclear chemical shift correlation (HETCOR) experiments were carried out to confirm the composition of the L-PCCM crystals. The ${ }^{1} \mathrm{H}$ NMR spectrum of $\mathrm{L}_{\text {-PCCM }}\left(300 \mathrm{MHz}, \mathrm{D}_{2} \mathrm{O}\right)$ revealed two multiplets at $\delta$ 1.97-2.00 and 2.01-2.02 ppm for $3 \mathrm{H}$ and $1 \mathrm{H}$, respectively. Another multiplet appearing in the range from $3.33-3.40 \mathrm{ppm}$ was assigned for $2 \mathrm{H}$. One deshielded proton adjacent to the nitrogen and oxygen was observed as a doublet at 4.18 and $4.19 \mathrm{ppm} .{ }^{13} \mathrm{C}$ NMR revealed peaks at 23.9, 29.0, 46.3 and $61.2 \mathrm{ppm}$ for the four carbons of the ring. A down field peak at $\mathbf{1 7 4 . 9} \mathrm{ppm}$ was assigned as $>\mathrm{C}=\mathrm{O}$. The assignment of the peaks was added by HETCOR data.

\subsection{Birefringence and $\mathrm{Z}$ scan measurement analyses}

The crystal was cut and polished to get a plate perpendicular to the (440) crystallographic axis. The polished plate was placed in a birefringence interferometer for measuring the variation in birefringence across the sample cross-section and per unit thickness. The birefringence interferogram obtained for the L-PCCM crystal plate of dimensions $4.12 \times$ $8.0 \times 1.76 \mathrm{~mm}^{3}$ is shown in Fig. 6. The principle and optical

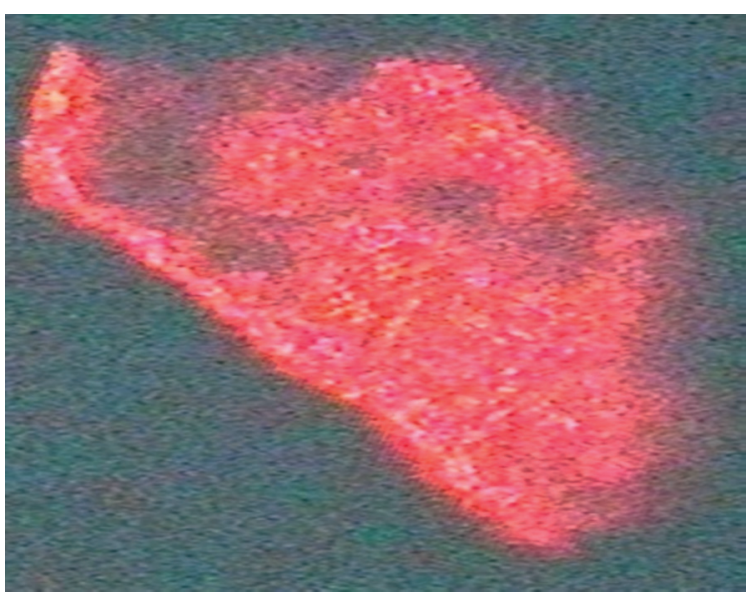

Fig. 6 Birefringence interferogram of the L-PCCM crystal. schematics of birefringence interferometry has been described by Verma \& Shlichta. ${ }^{23}$ The interferogram does not have any fringe in the entire cross section of the sample. This signifies that there is no appreciable variation in the birefringence of the crystal sample, and hence good optical homogeneity of the crystal. The dark patches in the top portion could be attributed to strain field in that region.

By using the open aperture Z-scan technique one can measure the third order non linearity of an L-PCCM single crystal. The polished sample is loaded to a computer controlled translation stage which moves along the $Z$-direction with respect to the incident laser beam. ${ }^{24}$ In this technique a Q-switched Nd:YAG laser of wavelength $532 \mathrm{~nm}$ is used to record the Z-scan curve Fig. 7(a). The optical limiting curve (transmission vs. input intensity) calculated from the Z-scan curve is shown in Fig. 7(b). The solid lines in the figures are theoretical fits to the experimental data following the nonlinear transmission equation. ${ }^{25}$ The numerically calculated two-photon absorption (2PA) coefficient of L-PCCM under the present excitation conditions is $3.52 \times 10^{-12} \mathrm{~m} \mathrm{~W}^{-1}$.

\subsection{Calculation of optical constant}

UV-Vis analysis was performed for the grown crystal which was recorded within the wavelength range of $200 \mathrm{~nm}$ to $900 \mathrm{~nm}$. The thickness of the crystal was $1.76 \mathrm{~mm}$. The transmission edge was observed at $225 \mathrm{~nm}$. The grown crystal had high transmission in the whole visible region. The various optical constants such as absorption coefficient, extinction coefficient, reflectance etc. were calculated by following the reported literature. ${ }^{12,26}$ The value of the absorption coefficient was obtained from the transmission data recorded by UV-Vis spectroscopy and is calculated by using

$$
\alpha=\frac{2.303 \times \log \left(\frac{1}{T}\right)}{t}
$$

where $t$ is the thickness of the sample.

The optical band gap can be calculated from the absorption coefficient and transmission spectrum, the optical band gap is given from the Tauc relation as

$$
\alpha h v=A\left(h v-E_{\mathrm{g}}\right)^{\frac{1}{2}}
$$

where $A$ is a constant, $E_{\mathrm{g}}$ is the optical band gap and $v$ is the incident frequency. Plotting a graph of $(\alpha h v)^{2} v s$. $h v$, the intercept between the straight line and the curve results in the value of the energy band gap. The value of the band gap energy is $5.988 \mathrm{eV}$. The extinction coefficient is obtained from the equation given as

$$
K=\frac{\lambda \alpha}{4 \Pi}
$$

The reflectance is obtained from the absorption coefficient and is calculated by the equation 


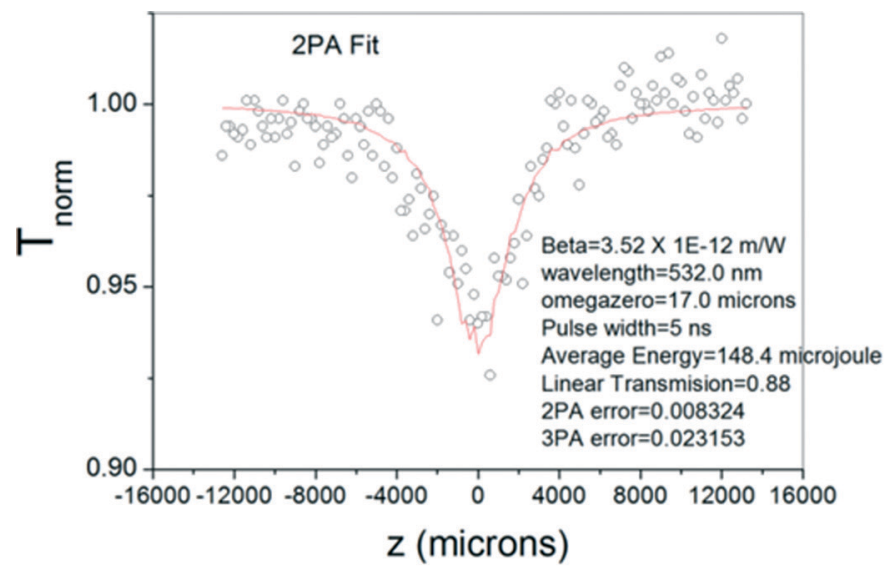

(a)

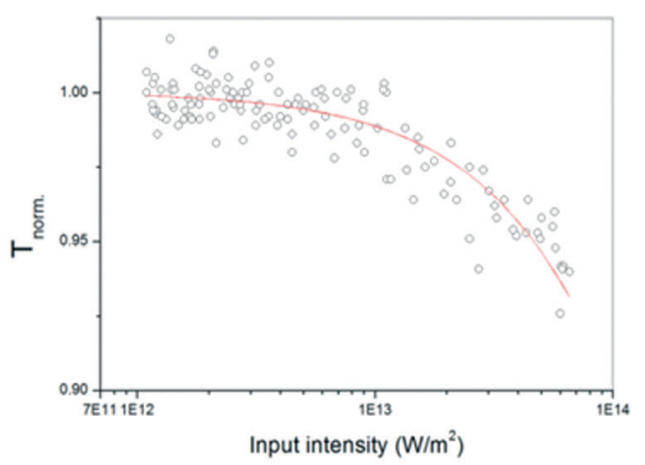

(b)

Fig. 7 (a) Open aperture Z-scan of L-PCCM. (b) Optical limiting curve of L-PCCM.

$$
R=\frac{\exp (-\alpha t)+\sqrt{\exp (-\alpha t) T-\exp (-3 \alpha t) T+\exp (-2 \alpha t) T^{2}}}{\exp (-\alpha t)+\exp (-2 \alpha t) T}
$$

The refractive index is evaluated from reflectance using the given equation

$$
n=-(R-1)+\frac{2 \sqrt{R}}{(R-1)}
$$

and the value of the refractive index $(n)$ is 2.7130 at $900 \mathrm{~nm}$.

The electrical susceptibility $\chi_{\mathrm{c}}$ is obtained by using the relation given below as

$$
\chi_{\mathrm{c}}=\frac{n^{2}-K^{2}-\varepsilon_{\mathrm{o}}}{4 \Pi}
$$

where $\varepsilon_{\mathrm{o}}$ is the dielectric constant in the absence of free charge carriers. From this relation, the value of electrical susceptibility is 0.37595 at $900 \mathrm{~nm}$. The real part of the susceptibility is given as $\varepsilon_{\mathrm{r}}=n^{2}-K^{2}$ and imaginary part is $\varepsilon_{\mathrm{i}}=2 n k$ and their values at $900 \mathrm{~nm}$ are 4.7219 and 0.002284 , respectively.

\subsection{Measurement of laser damage threshold and thermal parameters}

Most nonlinear optical single crystals are used as laser

\begin{tabular}{|c|c|c|c|c|}
\hline \multirow[b]{2}{*}{ Crystal } & \multicolumn{2}{|c|}{1 pulse per second } & \multicolumn{2}{|c|}{10 pulse per second } \\
\hline & $\mathrm{J} \mathrm{cm}^{-2}$ & MW $\mathrm{cm}^{-2}$ & $\mathrm{~J} \mathrm{~cm}^{-2}$ & MW $\mathrm{cm}^{-2}$ \\
\hline L-PCCM & 0.14 & 13.9 & 0.12 & 12 \\
\hline
\end{tabular}
sources. So, it is mandatory to determine their laser damage

Table 3 Laser damage threshold values of L-PCCM threshold at different laser powers. Laser damage threshold analysis was carried out using a Nd:YAG laser having a wavelength of $1064 \mathrm{~nm} .{ }^{27}$ The observed values of the laser damage threshold after a single shot and multiple shots are given in Table 3. From these analyses we understood that the single shot laser damage is higher than that of multiple shot damage threshold. From the above discussions we can understand that the material with a higher specific heat is more resistant to laser damage. This value is in tune with the observed specific heat which is given below. The higher value of LDT is useful for frequency conversion in laser devices.

In this study, the photopyroelectric (PPE) thermal wave technique was performed to measure different thermal transport properties of single crystals such as thermal diffusivity $(\alpha)$, thermal conductivity $(k)$, thermal effusivity $(e)$ and heat capacity $\left(c_{\mathrm{p}}\right)$. These parameters are critical for a nonlinear optical crystal for its use in fabricating devices because the optical damage threshold of a crystal is determined by its thermal conductivity and specific heat capacity, which determine the heat dissipation capability of the material. The thermal parameters which were determined from the above technique are given in Table 4.

\subsection{Photoluminescence}

In order to know the luminescent behavior of the L-PCCM single crystal, a PL spectrum was recorded using an Edinburg luminescence spectrometer (model: F900) under ambient conditions. The recorded spectrum is shown in Fig. 8. This analysis will give important information about the absorption and emission of light. The emission spectrum corresponded to an excitation wavelength of $314 \mathrm{~nm}$. From the figure, one can see that the peak at $475 \mathrm{~nm}$ suggests that the material is a good candidate for blue light emission and has less defects. These results are in tune with the recorded HRXRD measurements. 
Table 4 Thermal parameters of the L-PCCM single crystal

\begin{tabular}{llllll}
\hline Sample code & $\begin{array}{l}\text { Density } \rho \\
\left(\mathrm{kg} \mathrm{m}^{-3}\right)\end{array}$ & $\begin{array}{l}\text { Thermal effusivity } e \\
\left(\mathrm{~W} \mathrm{~s} \mathrm{~s}^{1 / 2} \mathrm{~m}^{-2} \mathrm{~K}^{-1}\right)\end{array}$ & $\begin{array}{l}\text { Thermal diffusivity } \alpha \\
\left(\times 10^{-6} \mathrm{~m}^{2} \mathrm{~s}^{-1}\right)\end{array}$ & $\begin{array}{l}\text { Thermal conductivity } k \\
\left(\mathrm{~W} \mathrm{~m}^{-1} \mathrm{~K}^{-1}\right)\end{array}$ & $\begin{array}{l}\text { Sp. heat capacity } C_{\mathrm{p}} \\
\left(\mathrm{J} \mathrm{kg}^{-1} \mathrm{~K}^{-1}\right)\end{array}$ \\
\hline L-PCCM & 2130 & $3279 \pm 6$ & $2.54 \pm 0.40$ & $5.14 \pm 0.45$ & $1012 \pm 20$
\end{tabular}

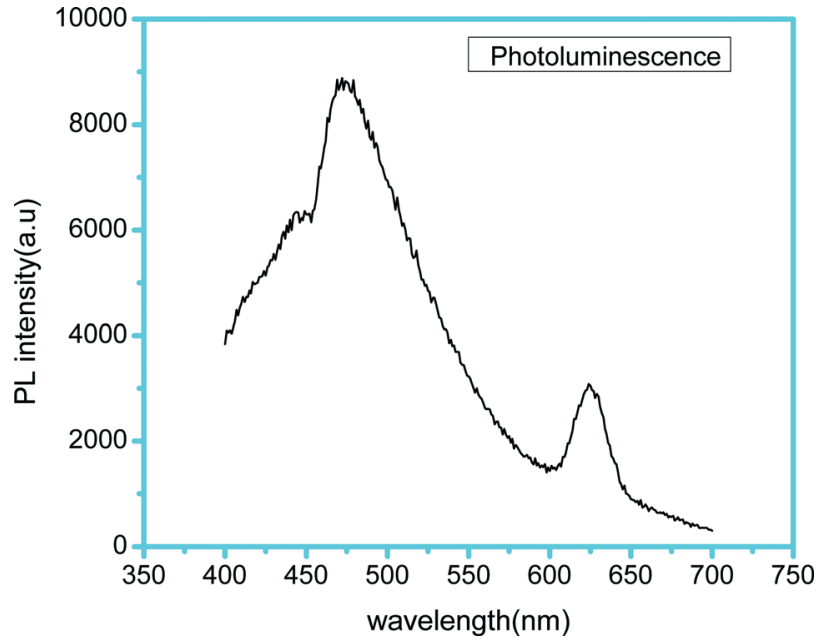

Fig. 8 Photoluminescence spectrum of L-PCCM.

\subsection{Piezoelectric and ferroelectric measurements}

The piezoelectric measurements for the L-proline cadmium chloride single crystal were carried out by using a PM-200 piezometer system with a frequency of $110 \mathrm{~Hz}$ and a dynamic force of $0.25 \mathrm{~N}$ at ambient conditions. The polished surface of (440) was chosen and then coated by silver paste in a thickness of $\sim 0.9 \mathrm{~mm}$ to make proper electrical contacts. The specimen was placed between the probes, and then a force was gently applied. The observed value of $d_{33}$ is $0.7 \mathrm{pC} \mathrm{N}^{-1}$.

The ferroelectric behavior of the samples was assessed by a ferroelectric loop tracer (make: Marine India). The defect free single crystal which was grown in (440) was taken, and then coated with silver paste on both sides, which acted as an electrode. The area of the electrode was $60.48 \mathrm{~mm}^{2}$ and the thickness of the sample was $4.14 \mathrm{~mm}$. Then the sample was placed in the holder and an electric field was applied. A graph was then plotted between polarization and electric field and is shown in Fig. 9. From the measurements we have come to the conclusion that the title compound has a paraelectric nature.

\subsection{Phase matching studies}

The title compound's second harmonic behavior was confirmed by a Kurtz powder technique by adopting a Q-switched Nd:YAG laser (wavelength $1064 \mathrm{~nm}$ ) having an input energy beam of $4.7 \mathrm{~mJ}$ per pulse. The powdered sample of L-PCCM with different particle sizes ranging from $25 \mu \mathrm{m}$ to $125 \mu \mathrm{m}$ was analyzed. In the present study, KDP (potassium dihydrogen orthophosphate) was taken as a reference. The different size specimens were placed in a thin glass capillary

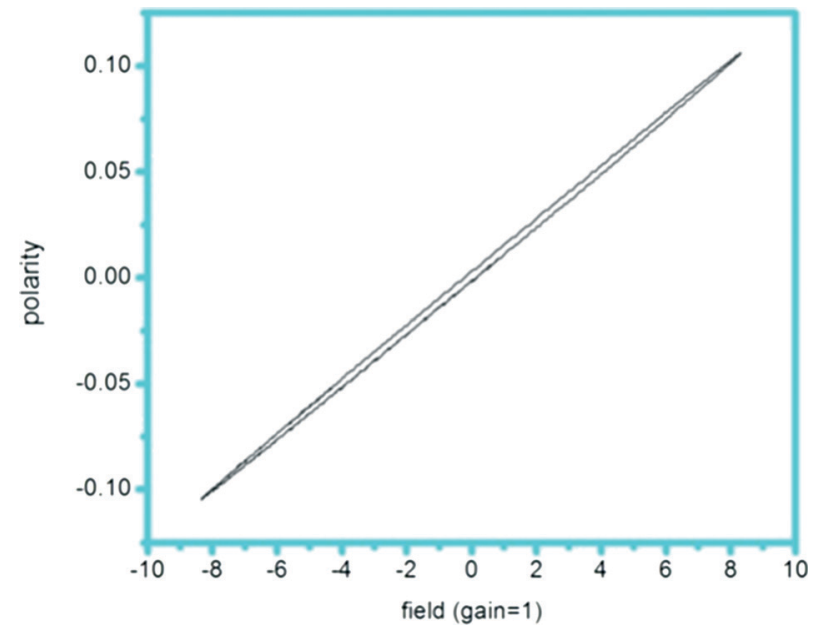

Fig. 9 Variation of applied electric field with polarisation.

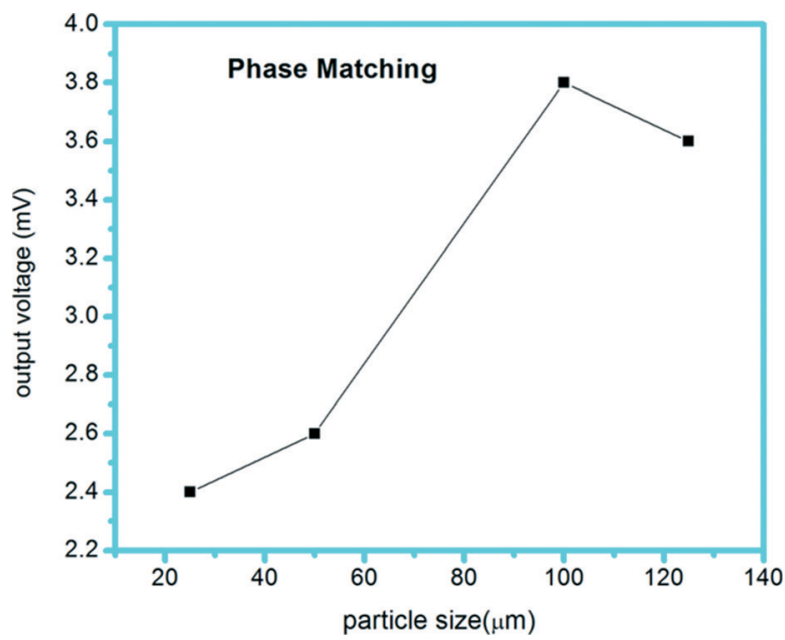

Fig. 10 Output voltage vs. particle size of the L-PCCM powder.

with a diameter of $1 \mathrm{~mm}$. We observed noticeable changes in the output power of the specimen. Its SHG value increased with an increase in particle size. After 100 microns, it almost attained saturation (as shown in Fig. 10). This confirms the phase matching behavior of the specimen.

\section{Conclusions}

A good quality single crystal of L-proline cadmium chloride was grown by a slow evaporation solution growth technique using double distilled water as the solvent. The grown single crystal was subjected to different characterization analyses in order to find its suitability for device fabrications. Its lattice 
dimensions and its crystallinity were examined by powder $\mathrm{X}$-ray and high resolution X-ray diffraction techniques. Its functional groups were identified by FTIR, RAMAN and NMR analyses. Its optical properties were assessed by PL and birefringence measurements. Its high value of specific heat shows the title compound is highly resistant to laser induced damage. Its third order nonlinear properties have been determined by a Z-scan technique.

\section{Acknowledgements}

The authors are highly thankful to Dr. R.C. Budhani, Director, NPL for his constant support and encouragement. One of the authors (K.T) is thankful to U.G.C (University of Grant Commission) for providing the research fellowship. She is also thankful to Prof. Dr. Reji Philip, RRI, Bangalore and Dr. Balachandran, GAC, Musiri and Dr. D. Haranath, CSIR-NPL for their kind help.

\section{References}

1 B. Riscob, M. Shakir, J. Kalyana Sundar, S. Natarajan, M. A. Wahab and G. Bhagavannarayana, Spectrochim. Acta, Part A, 2011, 78, 543-548.

2 K. Meera, R. Muralidharan, R. Dhanasekaran, P. Manyum and P. Ramasamya, J. Cryst. Growth, 2004, 263, 510-516.

3 R. Ramesh Babu, N. Vijayan, R. Gopalakrishnan and P. Ramasamy, Cryst. Res. Technol., 2006, 41, 405-410.

4 M. D. Aggarwal, J. Stephens, A. K. Batra and R. B. Lal, J. Optoelectron. Adv. Mater., 2003, 5, 555.

5 T. Uma Devi, N. Lawrence, R. Ramesh Babu, K. Ramamurthi and G. Bhagavannarayana, J. Miner. Mat. Charact., 2009, 8, 393-403.

6 S. Suresh, A. Ramanand, D. Jayaraman and P. Mani, Rev. Adv. Mater. Sci., 2012, 30, 175-183.

7 Y. Yukawa, Y. Inomata and T. Takeuchi, Bull. Chem. Soc. Jpn., 1983, 56, 2125-2128.

8 A. Kanadsamy, R. Siddeswaran, P. Suresh Kumar and R. Mohan, Cryst. Growth Des., 2007, 7, 183-186.

9 M. Shakir, S. K. Kushwaha, K. K. Maurya, R. C. Bhatt, Rashmi, M. A. Wahab and G. Bhagavannarayana, Mater. Chem. Phys., 2010, 120, 566-570.
10 P. Koteeswari, S. Suresh and P. Mani, American Journal of Condensed Matter Physics, 2012, 2, 116-119.

11 S. K. Kushwaha, K. K. Maurya, D. Haranath and G. Bhagavannarayana, J. Appl. Crystallogr., 2011, 44, 1054-1061.

12 A. Krishna, N. Vijayan, B. Riscob, B. S. Gour, D. Haranath, J. Philip, S. Verma, M. S. Jayalakshmy, G. Bhagavannarayana and S. K. Halder, Appl. Phys. A, 2013, DOI: 10.1007/s00339-0137902-1.

13 H. Ratajczak, J. Baryck, A. Pietraszko, S. Debrus, M. May and J. Venturini, J. Mol. Struct., 2000, 526, 269-278.

14 M. Diem, P. L. Polavarupu, M. Obodi and L. A. Nafie, J. Am. Chem. Soc., 1982, 104, 3329-3336.

15 A. J. D. Moreno, P. T. C. Freire, I. Guedes, F. E. A. Melo, J. Mendes-Filho and J. A. Sanjurjo, Braz. J. Phys., 1999, 29, 380-387.

16 J. L. Bredas, C. Adant, P. Tackx and A. Persoons, Chem. Rev., 1994, 94, 243-278.

17 H. S. Nalwa, M. Hanack, G. Pawlowski and M. K. Engel, Chem. Phys., 1999, 245, 17-26.

18 D. M. Burland, R. D. Miller and C. A. Walsh, Chem. Rev., 1994, 94, 31-75.

19 C. R. Zhang, H. S. Chen and G. H. Wang, Chem. Res. Chin. Univ., 2004, 20, 640-646.

20 Y. Sun, X. Chen, L. Sun, X. Guo and W. Lu, Chem. Phys. Lett., 2003, 381, 397-403.

21 O. Christiansen, J. Gauss and J. F. Stanton, Chem. Phys. Lett., 1999, 305, 147-155.

22 R. T. Lynch Jr, M. D. Levenson and N. Bloembergen, Phys. Lett. A, 1974, 50, 61-62.

23 S. Verma and P. J. Shlichta, Prog. Cryst. Growth Charact. Mater., 2008, 54, 1-120.

24 Neelam Rani, N. Vijiyan, Kanika Thukral, K. K. Maurya, D. Harnath, G. Bhagavannarayana and S. Verma, Spectrochim. Acta, Part A, 2013, 105, 192-199.

25 M. Sheik-Bahae, A. Said, T.-H. Wel, D. J. Hagan and E. W. Van Stryland, IEEE J. Quantum Electron., 1990, 26, 760-769.

26 S. Suresh, P. Mani and K. Anand, Int. J. Comp. Appl., 2012, 43, 0975-8887.

27 N. Rani, N. Vijayan, B. Riscob, S. Karan Jat, A. Krishna, S. Dhas, G. Bhagvannarayana, B. Rathi and M. A. Wahab, CrystEngComm, 2013, 15, 2127-2132. 